\title{
The effects of robusta coffee on tooth discolouration
}

\author{
Chu Chin Sin*, Ayu Trisna Hayati*, Endang Sukartini* \\ *Department of Conservative Dentistry Faculty of Dentistry Universitas Padjadjaran
}

\begin{abstract}
Introduction: One of the most frequent dental problems that confronted dentist is tooth discoloration which can cause significant cosmetic problems. Extrinsic tooth discoloration occurs when stain forms on the tooth surface or in the pellicle and the common causes of extrinsic tooth discoloration is coffee. Robusta coffee contains high level of chromogenic compound which can incorporate itself into the acquired pellicle and tannic acids that can denature the pellicle protein and increase its stain ability. The purpose of this experiment was to investigate the tooth discoloring effect of Robusta coffee solution. Methods: This research type was a true experiment (in vitro) using 30 samples of maxillary first premolar whose roots had been cut until the CEJ. Samples were divided into 2 groups (which are soaked in Robusta coffee solution and the other in mineral water) of 15 , with a frequency of three times daily for seven days. The difference in tooth color changes was measured by using a spectrophotometer. Results: This research was analyzed by using t-test and there was a significant difference between the two groups ( $p$-value $\leq 0.00$ ). Conclusion: Robusta coffee effected to tooth discoloration.
\end{abstract}

Keywords: Extrinsic tooth discolouration, robusta coffee, chromogen, tannic acid.

\section{INTRODUCTION}

In today modern times, society is concerned about aesthetic issues due to psychological or social status facts. The teeth greatly influences the facial esthetic because teeth and is easily diminishes due to tooth discoloration or malposition. ${ }^{1}$

Tooth discoloration is defined as coloration of teeth that is other than the white to yellowishwhite of normal teeth and can be classified either intrinsic or extrinsic. Intrinsic discoloration occurs following a change to the structural composition or thickness of the dental hard tissues. Extrinsic discoloration is outside the tooth substance and lies on the tooth surface or in the acquired pellicle.
The most common causes of extrinsic discoloration are smoking, tea, red wine and coffee. These four culprits are all things that most people are not willing to give up just to have whiter teeth. ${ }^{2,3}$

In Indonesia more than $70 \%$ of all coffee produced is Robusta coffee. Robusta beans are far cheaper to produce and are sold at lower prices. According to "Indonesian Trade Statistics", due to its relative cheap price, most of it is used in instant coffee and other manufactured products. ${ }^{4}$

Coffee is also known for their psychoactive effect, with stimulating effects on the central nervous and can also alleviate fatigue, increase wakefulness, and improve concentration and focus but regular coffee intake can have a deleterious effect on teeth; over time, teeth will

Corresponding author: Ayu Trisna Hayati, Department of Conservative Dentistry, Faculty of Dentistry Universitas Padjadjaran, Indonesia. Jalan Sekeloa Selatan I, Bandung, West Java, Indonesia, 40132; Phone: +6222-2504985/2532805 
become stained, even in spite of regular toothbrushing and flossing. Previous research done by Ghavamnasiri in 2004 on enamel staining after application of bleaching showed that coffee can cause tooth discoloration by immersing bovine incisors in coffee for half an hour daily for three weeks, the end results showed significant color difference. In another research done by Lee and his associates in 2010 showed that the color of teeth changed to dark brown due to staining with coffee after application of tooth bleaching. In a research done by Torres and his associate to test bleaching efficiency in 2009, tooth sample were immersed in coffee, 14 day later the teeth attain to a shade close to $C 4 .{ }^{5,6,7,7,9,10}$

According to Baig and his associates in 2005, coffee contains chromogen. Chromogen is a term used to describe that complete arrangement of atoms that gives rise to the observed light. Based on a research done by Mehrotra and her associates in 2011 on disorder of teeth in association with chlorohexidine, they stated that patients who consumed greater quantities of chromogens experienced more staining and staining is not proportional to the chlorohexidine concentration. ${ }^{11,12,13}$

Research done by Tabasum and his associates in 2001 to estimate the tannin content normally found in Pakistan food showed that roasted coffee contain 0.35-0.4 percent of tannin. Tannic acid has a strong denaturing effect on pellicle protein. Research done by Norbo showed that tannic acid is capable of discoloring the dental pellicle, both in vitro and in vivo. Stimmelmayr and his associates done a research in 2006 on incisor tooth breakage and enamel defects, they stated that the consumption tannin rich forage is most likely the cause of the brown-black discoloration in their sample. ${ }^{14,15,16,17}$

The purpose of this research is to analyzed the tooth discoloration effects of Robusta coffee solution performed with a frequency exposure of 3 times per day for 7 days. As a control group bottled mineral water will be used with a frequency of 3 times per day for 7 days.

\section{METHODS}

The research tools are light spectrophotometer, cups for soaking tooth, writing materials, measurement glass, stop watch, polish brush, and high speed hand piece. In this research the materials used were thirty mandibular firstpremolar teeth, Robusta coffee powder, artificial saliva type AFNOR and nail varnish.

Due to interhuman differences in the perception of color, visual shade assessment of human teeth to compare tooth discoloration is lacking standardization that may be improved by the use of a spectrophotometer and can eliminate the subjective interpretation. The spectrophotometer measures the intensity of light that is reflected by an object at numerous wavelengths of visible light. ${ }^{18}$

In this experiment, the tooth color change is determined by measuring the tooth color by the spectrophotometer before and after exposure to immersion of tooth specimen in Robusta coffee solution and compared to the result of that immersed in mineral water as a control.

Thirty mandibular first-premolars were selected and whose root was cut at CEJ line with high speed hand piece. The cutted surface below the CEJ line was then varnished with nail polish, and kept in artificial saliva. The teeth colors were then measured with a spectrophotometer for the initial tooth color. The thirty teeth were divided into two groups of 15 .

The first group was immersed in coffee for 30 seconds, removed and immediately immersed in artificial saliva for another 30 seconds. These two immersions was repeated for 5 times with a total of 10 immersions ( 5 in Robusta coffee and 5 in mineral water) and lastly kept in artificial saliva to form a soaking cycle. This soaking cycle is repeated for three times a day for seven days. Lastly the tooth is then measured again with the spectrophotometer for the final tooth color. As a control the second groups of 15 teeth were immersed in mineral water instead of coffee and with the same frequency.

\section{RESULTS}

The results of the degree of tooth discoloration before and after soaking are presented as statistical data which include the mean, and the standard deviation as shown in Table 1.

From Table 1, the mean value of the degree 
of tooth discoloration from Group I is 6.689 , and group II 1.646. The difference degree of tooth discoloration of these two groups is illustrated at Figure 1.

Figure 1 showed the mean value of the degree of tooth discoloration of the two groups. Of the two groups, Group I showed more difference before and after soaking in Robusta coffee solution compared to those soaked in mineral water.

Statistical test is done to know if there is a difference between Robusta coffee and mineral water to the level of discoloration on the tooth specimens. The degree of tooth discoloration data is analyzed using the t- test, which is presented in Table 2.

Since the significance value is $\leq 0.05$ to reject $H_{0}$ in the t-test as showed above, the result of the test showed significant difference. Therefore, there is a difference in the effect of tooth discoloration between coffee and water.

Table 1. Degree of Changes of Tooth Color Before and After Exposure

\begin{tabular}{|c|c|c|c|c|}
\hline Group & Sample Number & Degree of Discoloration & Mean & Standard Deviation \\
\hline & 1 & 7.899 & & \\
\hline & 2 & 6.856 & & \\
\hline & 3 & 5.035 & & \\
\hline & 4 & 6.621 & & \\
\hline & 5 & 7.463 & & \\
\hline & 6 & 7.359 & & \\
\hline \multirow[t]{2}{*}{ Group } & 7 & 6.892 & & \\
\hline & I & 5.671 & 6.671 & 8.9787 \\
\hline \multirow[t]{14}{*}{ (Coffee) } & 8 & & & \\
\hline & 9 & 6.854 & & \\
\hline & 10 & 6.238 & & \\
\hline & 11 & 6.689 & & \\
\hline & 12 & 6.753 & & \\
\hline & 13 & 7.192 & & \\
\hline & 14 & 5.368 & & \\
\hline & 15 & 7.173 & & \\
\hline & 1 & 1.471 & & \\
\hline & 2 & 2.607 & & \\
\hline & 3 & 0.928 & & \\
\hline & 4 & 2.0761 & & \\
\hline & 5 & 0.491 & & \\
\hline & 6 & 2.786 & & \\
\hline \multirow[t]{2}{*}{ Group } & 7 & 0.416 & & \\
\hline & II & 1.671 & 1.493 & 2.3358 \\
\hline \multirow[t]{8}{*}{ (Water) } & 8 & & & \\
\hline & 9 & 1.361 & & \\
\hline & 10 & 1.969 & & \\
\hline & 11 & 0.834 & & \\
\hline & 12 & 1.926 & & \\
\hline & 13 & 2.398 & & \\
\hline & 14 & 0.432 & & \\
\hline & 15 & 1.034 & & \\
\hline
\end{tabular}




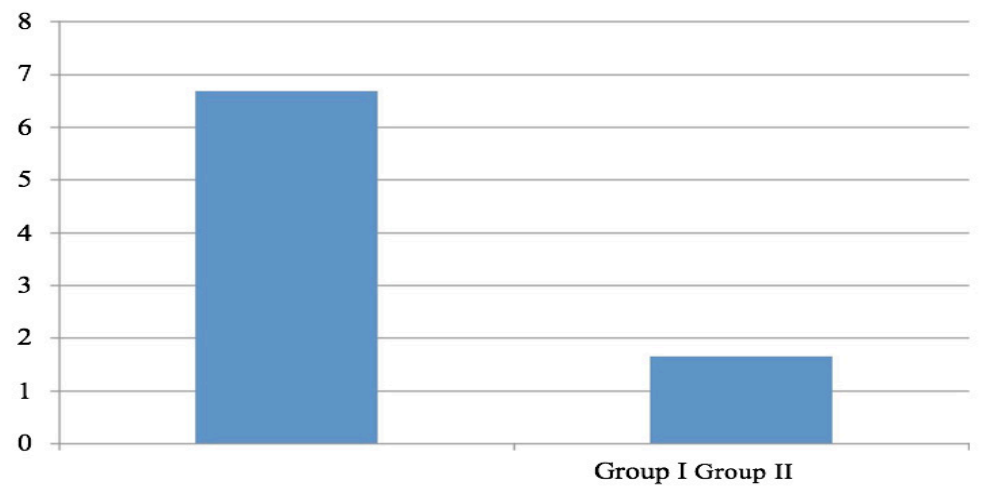

Figure 1. Difference of Tooth Color Discoloration Before \& After Exposure.

Table 2. Result of t-test

\begin{tabular}{lcccccc}
\hline & Mean & $\mathrm{t}$ count & $\mathrm{df}$ & $\mathrm{t}$ table & $\mathrm{p}$ value (sig) & Description \\
\hline Coffee & 6.671 & 17.880 & 28 & 2.048 & 0.000 & Ho rejected \\
Water & 1.493 & & & & & \\
\hline
\end{tabular}

\section{DISCUSSION}

Extrinsic discoloration occurs outside the tooth substance and lies on the tooth surface or in the acquired pellicle. The mechanism involved is the denaturation of the pellicle protein by tannic acid and incorporation of chromogenic compound into the acquired pellicle. ${ }^{19,20}$

Roasted coffee contains $18 \pm 1.7 \mathrm{mg} \mathrm{g}^{-1}$ tannic acid. Tannic acid has a strong denaturing effect on the pellicle protein. The denatured pellicle protein will then increase its stain ability. In addition, Robusta coffee contains chromogens. During the formation of the pellicle, saliva proteins are selectively bonded onto the enamel surface via calcium bridges, chromogens then interact with the pellicle via hydrogen bridges. These chromogens are taken up by the pellicle and the color imparted is determined by the natural color of the chromogen. ${ }^{21,22,23}$

The mean of the two groups showed big difference with Group I 6.671 and Group II 1.493. Statistical analysis using t-test also confirmed it and showed significant difference of tooth discoloration between the two groups.

Group I, immersion of tooth specimen in Robusta coffee, showed significant difference compared to Group II, which was immersion of tooth specimen in water. This shows that Robusta coffee will cause tooth discoloration. This result shares similarities to the research done by
Koksal and Dikbas in 2007 where the staining ability of various agents were tested, end result showed coffee produces the most significant color difference among coffee, tea and cola. ${ }^{24}$ This similarity may be caused by the highest chromogen content in coffee among the three solutions above. ${ }^{24}$

The result above also shares similarity with the research done by Nordbo where tannic acid can cause discoloration of the dental pellicle both in vitro and in vivo. Erikson and Nordbo explained that tannic acid denatures the pellicle proteins and increase its stain ability. The pellicle may be exposed to a variety of denaturing agents under normal conditions. Tannic acid has a strong denaturing effect on pellicle proteins. It occurs as a natural constituent of various fruit, wines, tea and coffee. ${ }^{14,19}$

\section{CONCLUSION}

Robusta coffee effected to tooth discoloration.

\section{REFERENCES}

1. Miloro M, Kolokythas A. (Eds.). Management of complications in oral and maxillofacial surgery. Hoboken: John Wiley \& Sons, Inc; 2011.

2. Mennito, A. S. 2006. A simple guide to tooth whitening. The dental learning 
network. Available online at: http:// www.dentallearning.org/course/fde0040/ coursebook.pdf. (Accessed on March 2012).

3. Garg, N. and Garg A. 2010.Textbook of Operative Dentistry. India. Jaypee. 249-253 pp.

4. Ukers, W. H. 2010. All About Coffee by William H. Ukers (Second Edition). Martino. 78-79. Available from: http://www.gutenberg.org/ ebooks/28500. (Access on July, 2012)

5. Ghavamnasiri, M and Habibi-Rad A. 2005. Effect of a $16 \%$ carbamide peroxide bleaching gel on enemal staining suscepbility. Iran. Journal of Dentistry. Available from: http:// journals.tums.ac.ir/upload_files/pdf/_/1806. pdf. (Accessed on March 2012).

6. Torres, C. R. G., et al. 2009. Influence of the cuantity of coloring agent in bleaching gels activated with LED/LASER appliances on bleaching efficiency. The European Journal of Esthetic Dentistry Volume 4 .

Available fromt: http://www.ncbi.nlm.nih. gov/pubmed/19655654. (Access on April, 2012)

7. Lee H. L., et al. 2010. Atmospheric pressure plasma jet composed three electrodes: application to tooth bleaching. Weinheim. Plasma Process. Available from: http:// pamg.postech.ac.kr/paper/Atmospheric\%20 Pressure\%20Plasma\%20Jet\%20Com posed\%20 of\%20Three\%20Electrodes.pdf. (Accessed on March 2012).

8. Attwood, A, et al. 2007. Differential responsiveness to caffeine and perceived effects of caffeine in moderate and high regular caffeine consumers. Psychopharmacology. Available from: http://connection.ebscohost. com/c/articles/23849937/differentialresponsiveness-caffeine-perceived-effectscaffeine-moderate-high-regular-caffeineconsumers. (Accessed on June 2012).

9. Simmons GF, Smilanick JL, John S, Margosan DA. Reduction of microbial populations on prunes by vapor-phase hydrogen peroxide. J Food Prot. 1997;60(2):188-191.

10. Soenarto, P. 2012. The taste of toraja. Pudji Lestari. Available online at: http://pudjilestari.wordpress.com/tag/ pranoto-soenarto/. (Accessed on March 2012).

11. Heaton, et al. 1997. The Chemical Industry. UK: Chapman \& Hall. 143-144 pp

12. Baig, A. et al. 2005. Extrinsic whitening effects of sodium hexametaphosphate- a review including a dentrifries with stabilized stannous fluoride. Compendium. Available from: http:// www.ncbi.nlm.nih.gov/pubmed/16999010. (Accessed on March 2012).

13. Mehrotra, V. et al. 2011. Drug induced disorder of teeth - an eye opener. Bagladesh. Bangladesh Research Publictions Journal. Available from: http://www. bdresearchpublications.com/admin/journal/ upload/09201/09201.pdf. (Accessed on June 2012).

14. Nordbo, H. 1977. Discoloration of dental pellicle by tannic acid. Acta Odontologica Scandinavica, Volume 35. Available from: http://informahealthcare.com/doi/ 